\title{
Copper-Doped CdSe/ZnS Quantum Dots: Controllable Photoactivated Copper(I) Cation Storage and Release Vectors for Catalysis**
}

\author{
Joseph C. Bear, Nathan Hollingsworth,* Paul D. McNaughter, Andrew G. Mayes, \\ Michael B. Ward, Thomas Nann, Graeme Hogarth, and Ivan P. Parkin*
}

\begin{abstract}
The first photoactivated doped quantum dot vector for metal-ion release has been developed. A facile method for doping copper(I) cations within ZnS quantum dot shells was achieved through the use of metal-dithiocarbamates, with $\mathrm{Cu}^{+}$ ions elucidated by X-ray photoelectron spectroscopy. Photoexcitation of the quantum dots has been shown to release $\mathrm{Cu}^{+}$ ions, which was employed as an effective catalyst for the Huisgen $[3+2]$ cycloaddition reaction. The relationship between the extent of doping, catalytic activity, and the fluorescence quenching was also explored.
\end{abstract}

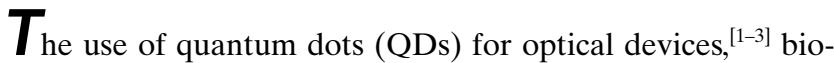
imaging agents, ${ }^{[4,5]}$ and energy materials ${ }^{[6]}$ has been the subject of intensive research, but their photoactivated properties have been largely overlooked as vectors for the controlled release of catalytic metals. ${ }^{[7]}$ Herein we demonstrate that $\mathrm{Cu}$ doped $\mathrm{CdSe} / \mathrm{ZnS}$ QDs act as vectors for the photoinduced release of $\mathrm{Cu}^{+}$ions for catalysis. The overgrowth of a shell composed of a semiconducting material such as $\mathrm{ZnS}$ with a larger band-gap (type-I core-shell system) than the QD core passivates the QD surface and leads to much improved photostability and decreased cytotoxicity. ${ }^{[8]}$ The thickness of the shell, as well as the presence of dopants has been shown to

[*] J. C. Bear, Dr. N. Hollingsworth, Dr. G. Hogarth, Prof. I. P. Parkin Department of Chemistry, University College London 20 Gordon Street, London, WC1H OAJ (UK)

E-mail: n.hollingsworth@ucl.ac.uk i.p.parkin@ucl.ac.uk

Dr. P. D. McNaughter, Dr. A. G. Mayes

School of Chemistry, University of East Anglia

Norwich Research Park, Norwich, Norfolk, NR4 7TJ (UK)

Dr. M. B. Ward

Institute of Materials Research, School of Process

Environmental and Materials Engineering (SPEME)

University of Leeds, Leeds, LS2 9JT (UK)

Prof. T. Nann

Ian Wark Research Institute, University of South Australia

Mawson Lakes Boulevard, Adelaide, SA 5095 (Australia)

[**] We are grateful to Dr. Stanislav Strekopytov for the ICP-MS analysis at the Imaging and Analysis Centre, Natural History Museum, London. We also thank the Leeds EPSRC Nanoscience and Nanotechnology Facility for equipment access and the EPSRC for funding N.H.

Supporting information for this article is available on the WWW under http://dx.doi.org/10.1002/anie.201308778.

of (C) 2013 The Authors. Published by Wiley-VCH Verlag GmbH \& Co. $\mathrm{KGaA}$. This is an open access article under the terms of the Creative Commons Attribution License, which permits use, distribution and reproduction in any medium, provided the original work is properly cited. dictate QD luminescence properties, ${ }^{[9]}$ which we herein link to catalytic potential.

Past studies on $\mathrm{Cu}$ doping have focused on doping the QD core, resulting in emission-tunable nanoparticles with enhanced luminescence properties and long-lived photoinduced magnetization. ${ }^{[10]}$ When doped into $\mathrm{ZnS}$ QD cores, $\mathrm{Cu}$ has been shown in the $2+$ oxidation state and can act as a source of optically active holes. ${ }^{[11]}$ Crooker and co-workers have shown that photoexcitation allows the tuning of the paramagnetic $\mathrm{Cu}^{2+}$ species in the QD core. ${ }^{[12]}$ Doping $\mathrm{Cu}$ into the QD shells has been largely uninvestigated. This is possibly because of the detrimental effect $\mathrm{Cu}$ ions have on the QD luminescence. ${ }^{[13]}$ Indeed, QDs have demonstrated high sensitivity towards $\mathrm{Cu}$ ions, where the presence of $\mathrm{Cu}$ dramatically quenches the QD core photoluminescence. ${ }^{[14-16]}$ The oxidation state of $\mathrm{Cu}$ in $\mathrm{ZnS}$ shells has been discussed for a long time and it has been established that $\mathrm{Cu}$ adopts the $1+$ oxidation state in $\mathrm{ZnS}$ lattices, which was confirmed by our XPS measurements. ${ }^{[17]}$

Herein we show that doping small amounts of $\mathrm{Cu}$ into the ZnS QD shell partially quenches the QD core luminescence, but makes QDs photoactivated vectors for the release of catalytically active $\mathrm{Cu}^{+}$ions. We hypothesize that $\mathrm{S}$ in the $\mathrm{ZnS} / \mathrm{CuS}$ shell is slowly photooxidized to $\mathrm{SO}_{x}{ }^{y-}$ on irradiation, which causes $\mathrm{Cu}^{+}$to be released into solution.

To evaluate this hypothesis, reactions which are selectively catalyzed by $\mathrm{Cu}^{+}$species such as the Huisgen $[3+2]$ cycloaddition developed by Sharpless ${ }^{[18]}$ and Meldal ${ }^{[19]}$ and co-workers have been employed. To the best of our knowledge, this is the first example of $\mathrm{CdSe} / \mathrm{ZnS}-\mathrm{CuS}$ QDs as $\mathrm{Cu}^{+}$vectors for heterogeneous catalysis.

Typically, QDs are shelled either by precursor injection, ${ }^{[20]}$ epitaxial growth ${ }^{[21]}$ or thermal decomposition. ${ }^{[22]}$ Herein CdSe core QDs were synthesized using a hot-injection method and shelled according to a modified procedure outlined by Dethlefsen and Døssing. ${ }^{[23]}$

The $\mathrm{Cu}$-doping of the $\mathrm{ZnS}$ shell used in this study was achieved using a new, one-pot low-temperature thermal decomposition of air-stable precursors in the presence of alkyl surfactants. The $\mathrm{Cu}$ dopant and $\mathrm{ZnS}$ shelling material were introduced as a stoichiometric mixture of copper(II) diethyldithiocarbamate $\left[\left(\mathrm{Cu}(\mathrm{DEDTC})_{2}\right)\right]$ and zinc(II) diethyldithiocarbamate $\left[\left(\mathrm{Zn}(\mathrm{DEDTC})_{2}\right)\right]$, respectively. Dithiocarbamates are promising single-source precursors for the synthesis of metal sulphide nanoparticles ${ }^{[24]}$ and have been used to great effect in ZnS QD shelling. ${ }^{[25,26]}$ Their use as dopant vectors in QD shells is underexplored, and given the wide array of metal dithiocarbamates, spanning the entirety of the 
periodic metals this shell-doping method has great scope given the myriad of new materials that can be formed.

CdSe cores were shelled by the decomposition of [ $\mathrm{Zn}$ $\left.(\text { DEDTC })_{2}\right]$ and $\left[\mathrm{Cu}(\text { DEDTC })_{2}\right]$ in the following molar ratios; 1:1 (I), 1:3 (II), 1:7 (III), 1:15 (IV), and 0:1 (V; see Table S1 in the Supporting Information). The total molar quantity of shell precursor was identical to that required for the $\mathrm{CdSe} / \mathrm{ZnS}$, equivalent to six monolayers. ${ }^{[23]}$

The presence of $\mathrm{Cu}$ in the QDs was shown by X-ray photoelectron spectroscopy (XPS). The molar ratios of $\mathrm{Cu}$ to $\mathrm{Zn}$ used in the QD shelling relates directly to the intensity of the $\mathrm{Cu}$ and $\mathrm{Zn}$ signals in the XPS spectra (Section S1). The $\mathrm{Cu} 2 \mathrm{p}_{3 / 2}$ and $\mathrm{Cu} 2 \mathrm{p}_{1 / 2}$ peaks for all samples are reported as 933.18 and $952.88 \mathrm{eV}$, respectively, which is indicative of the presence of $\mathrm{Cu}^{+}$ions. ${ }^{[13]}$

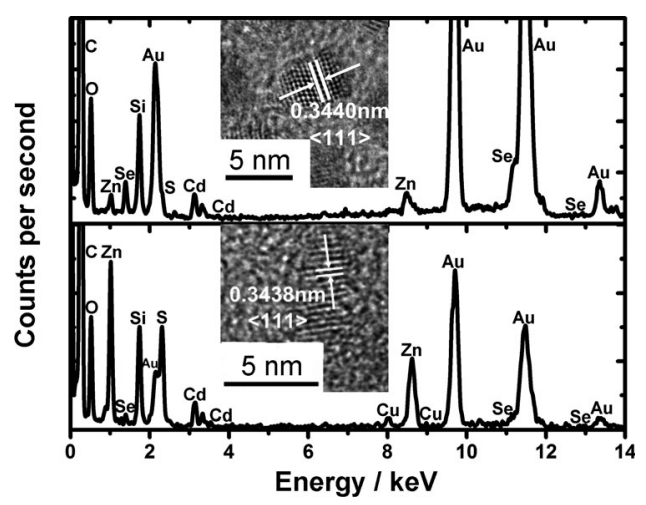

Figure 1. EDX spectra and HRTEM images of $\mathrm{CdSe} / \mathrm{ZnS}$ and $\mathrm{CdSe} /$ ZnS/CuS nanocrystals.

Energy-dispersive X-ray (EDX) spectroscopy (Figure 1) confirmed the presence of all of the elements in the structure (Cd, Se, Zn, S, and Cu), versus CdSe/ZnS QDs. Quantitative EDX analysis showed the amount of $\mathrm{Cu}$ loading on the QDs, all of which were low in comparison to the stoichiometric amounts of shelling reagents used (Table S1). XPS analysis gave higher $\mathrm{Cu}$-to-Zn ratios than EDX, thus suggesting the majority of $\mathrm{Cu}$ sites are located on the QD surface. We can also infer that the CdSe cores have a preferential affinity for $\mathrm{ZnS}$ over CuS shelling because of the higher amount of $\mathrm{Zn}$ in the system. Further characterization of $\mathrm{I}-\mathrm{V}$ by transmission electron microscopy (TEM) showed all samples to be monodisperse with an average diameter of 3.7 to $4.1 \mathrm{~nm}$ (Section S2). High-resolution TEM (HRTEM) measurements showed highly crystalline structures with d-spacings corresponding to the $\langle 111\rangle$ crystal plane of CdSe (see insets in Figure 1).

Figure $2 \mathrm{~A}$ shows the absorption and photoluminescence (PL) spectra of samples I-V. When $\mathrm{Cu}$ is introduced to the $\mathrm{ZnS}$ shell, a blue shift in luminescence and a decrease in quantum yield were observed. This is in stark contrast to a pure $\mathrm{ZnS}$ shell, where a significant increase in quantum yield and a red-shift in luminescence is observed. In the case of sample I, the PL was completely quenched. Furthermore, $\mathrm{Cu}$-doped samples did show an increased near-infrared PL band at approximately $1.8 \mathrm{eV}(660 \mathrm{~nm})$ (Figure 2B), which
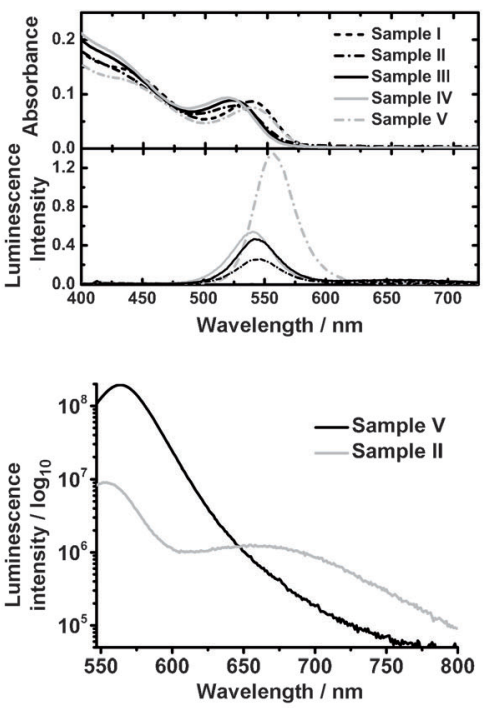

C
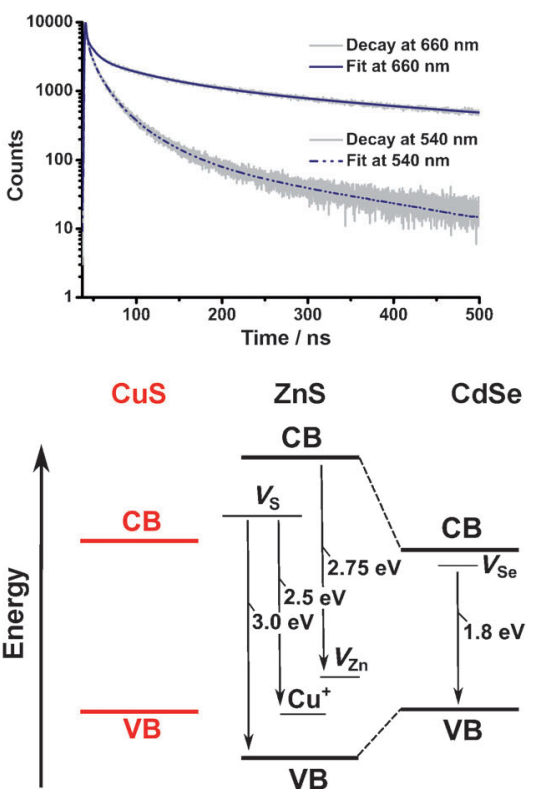

Figure 2. A) UV/Vis and fluorescence spectra of samples (I-V).

B) Fluorescence spectra of samples II and V clearly showing a second, broad emission band centered at $660 \mathrm{~nm}$ for sample II. C) Fluorescence decay measurements at 540 and $660 \mathrm{~nm}$, illustrating the longlived Cu-induced feature at $660 \mathrm{~nm}$. D) Proposed fluorescence energy level diagram.

had a significantly longer luminescence life-time compared with the band-edge luminescence (Figure 2D). If we assume that $\mathrm{Cu}^{+}$ions have been doped into the $\mathrm{ZnS}$ shell (which is reasonable given the low levels of $\mathrm{Cu}$ found in the particles experimentally), Figure $2 \mathrm{C}$ represents the energy levels in the QDs. ${ }^{[11,27-29]} \mathrm{Cu}$-doped $\mathrm{ZnS}$ shows luminescence in the blue/ green region of the spectrum because of $\mathrm{S}$ and $\mathrm{Zn}$ vacancies and a level introduced by the $\mathrm{Cu}^{+}$ions. ${ }^{[28]}$ This luminescence is not visible in our spectra and is most likely quenched by the CdSe core or not intense enough to be detected. The nearinfrared luminescence at about $1.8 \mathrm{eV}(660 \mathrm{~nm})$ is well-known in CdSe nanocrystals and can be assigned to $\mathrm{Se}$ or $\mathrm{Se} / \mathrm{Cd}$ (di)vacancies probably located at the boundary between core and shell. ${ }^{[27,30]}$ 
The blue-shift in the core luminescence may be due to a "shrinking" of the CdSe core or changes in its dielectric environment. Given the low levels of $\mathrm{Cu}$ doping, the $\mathrm{Cu}$ in the "shelling" reagents partially exchanged against $\mathrm{Cd}$. This is plausible bearing in mind work on $\mathrm{Cu}$ activation of chalcogenides and cation exchange. ${ }^{[13,31]}$ The "shrinking" theory is further supported by the increase in the near-infrared photoluminescence, which indicates that the number of defect states in the core has been increased-especially at the interface between core and shell.

$\mathrm{As} \mathrm{Cu}$ in the $\mathrm{ZnS}$ shell has $\mathrm{Cu}^{+}$character, excitation of the QDs is likely to oxidize the $\mathrm{Cu}$ dopants releasing $\mathrm{Cu}^{+}$ions into solution. The mechanism of release likely involves photooxidation of the doped $\mathrm{ZnS}$ shell under release of $\mathrm{Cu}$, $\mathrm{Zn}$, and $\mathrm{SO}_{x}{ }^{y-}$ ions. The proposed mechanism was supported by the detection of $\mathrm{Cu}$ using inductively coupled plasma-mass spectroscopy (ICP-MS). A QD suspension of I in hexane was irradiated with $254 \mathrm{~nm}$ overnight, with a counterpart QD suspension kept in the dark. The QDs were precipitated with ethanol, centrifuged, and the supernatant evaporated for nitric acid digestion and analysis. The irradiated sample leached about 14 times as much $\mathrm{Cu}$ compared to the dark sample, which supports the hypothesis of photooxidation promoted $\mathrm{Cu}^{+}$release (Section S3.5). The amount of copper leached is small (1033 $\mathrm{ng} \pm 10 \%$ from a total QD mass of $16.2 \mathrm{mg}$ ).

A practical way of using the as-generated $\mathrm{Cu}^{+}$species is the Huisgen $[3+2]$ cylcloaddition which is known to be catalyzed by $\mathrm{Cu}^{+}$sites more readily than $\mathrm{Cu}^{2+}$. The literature precedent is to start with a $\mathrm{Cu}^{2+}$ salt and generate in situ $\mathrm{Cu}^{+}$ for catalysis. ${ }^{[32]}$ Commonly used in situ reducing agents such as sodium ascorbate derivatives have drawbacks in bioconjugation applications because of separate reactions with protein side-chains. ${ }^{[3,34]}$ The groups of Bowman and Yagci have independently shown that separate $\mathrm{UV}$ and visible-light activators can be used to reduce $\mathrm{Cu}^{2+}$ to $\mathrm{Cu}^{+}$in a two component system using a radical reduction mechanism, however the selectivity of the radical photoreducing agent is unclear. ${ }^{[35-37]}$ As such, a system that can release $\mathrm{Cu}^{+}$in a controlled manner without the need for a reducing agent or radical initiator would be highly advantageous in bioconjugation.

Sample I, containing the highest amount of $\mathrm{Cu}$ doped in the $\mathrm{ZnS}$ shell (Section S7), was tested first. ${ }^{1} \mathrm{H}$ NMR spectroscopy was used to monitor the azide versus triazole ratio (Figure 3, $\mathrm{Ha}$ and $\mathrm{Hb}$, respectively). A concentration with $5 \mathrm{~mol} \%$ of $\mathrm{Cu}$ in hexane $(1 \mathrm{~mL})$ was shown to have reached $>99 \%$ yield within $2 \mathrm{~h}$. The insolubility of the triazole in hexane allows separation from the QDs by filtration. Analyzing aliquots at timed intervals by ${ }^{1} \mathrm{H}$ NMR spectroscopy shows 1, 2, 8, 35, and $100 \%$ of triazole formed at 15, 30, 60, 90, and 120 minutes, respectively. The slow initial product formation suggests there is an activation period after irradiation of 60 minutes. Presumably, this initial inactivity is due to the QDs being kept in the dark prior to use. The activation period could be postulated to be the time required for the release of $\mathrm{Cu}^{+}$ions and is therefore rate-limiting.

Performing the same reaction in the dark gave a $22 \%$ yield. Therefore, we postulate that on irradiation, the QDs

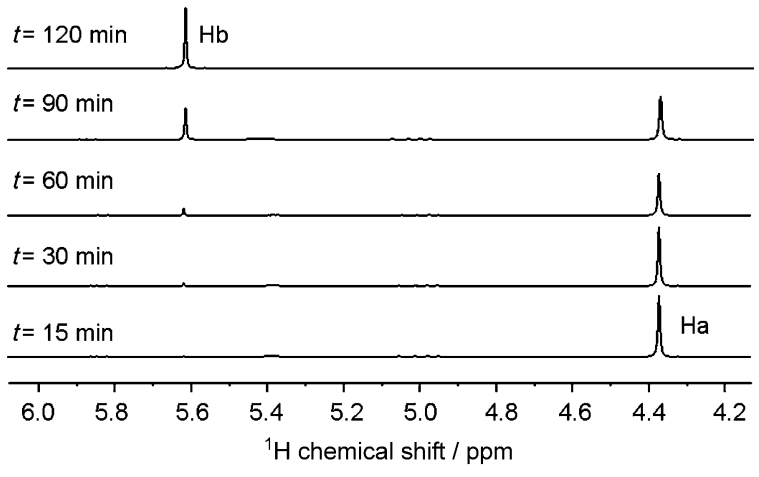

Figure 3. ${ }^{1} \mathrm{H}$ NMR spectroscopy of the azide-alkyne cycloaddition catalyzed by I (5 mol\% Cu).

photooxidize with $\mathrm{S}$ being oxidized to $\mathrm{SO}_{x}{ }^{y-}$. This causes the $\mathrm{Cu}$ to form a complex with the azide, which acts as a sacrificial electron acceptor and subsequently, the click reaction occurs.

Table 1: Summary of the Huisgen cycloaddition; yields are calculated using ${ }^{1} \mathrm{H}$ NMR data and are averages of three samples.

\begin{tabular}{lclllllc}
\hline Catalyst & $\begin{array}{c}\text { QD } \\
{[\mathrm{wt} \%]}\end{array}$ & $\begin{array}{l}\mathrm{Cu} \\
{[\mathrm{mol} \%]}\end{array}$ & $\begin{array}{l}T \\
{[\mathrm{~h}]}\end{array}$ & $\begin{array}{l}\text { Yield }+h v^{[\mathrm{d}]} \\
{[\%]}\end{array}$ & $\begin{array}{c}\text { TON } \\
{\left[\mathrm{h}^{-1}\right]^{[\mathrm{e}]}}\end{array}$ & $\begin{array}{l}\text { Tield-hv } \\
{[\%]}\end{array}$ \\
\hline none & 0 & 0.00 & 8 & $<0.1$ & 0 & 0 & 0 \\
I & 77.2 & 5.00 & 2 & $>99$ & 20 & 10 & 22 \\
I & 5 & 0.32 & 8 & $>99^{[\mathrm{a}]}$, & 309 & 39 & 11 \\
& & & & $>99^{[\mathrm{b}]}$, & & & \\
II & 5 & 0.16 & 8 & $>99$ & 625 & 78 & 5 \\
III & 5 & 0.12 & 8 & 7.50 & 61 & 8 & $<0.1$ \\
IV & 5 & 0.04 & 8 & 1.30 & 32 & 4 & $<0.1$ \\
V & 5 & 0.00 & 8 & $<0.1$ & 0 & 0 & $<0.1$ \\
\hline
\end{tabular}

[a], [b], [c] Repeats using the same catalyst. [d] $h v$ used; $257 \mathrm{~nm}$ $980 \mu \mathrm{Wcm}^{-1}$. [e] TOF $=$ turnover frequency.

Reducing the QD loading of I to $0.32 \mathrm{~mol} \%$ (5 wt \% of I) gives $>99 \%$ yield after $8 \mathrm{~h}$ (Table 1 ). Repeating three cycles using the same catalyst has no detrimental effect on yield showing the QD core is able to release catalytic $\mathrm{Cu}^{+}$over a prolonged period. On comparison, the lower level of doping in II reduces the mole percentage $(\mathrm{mol} \%)$ of $\mathrm{Cu}$ to $0.16 \%$ versus the same $5 \mathrm{wt} \%$ of QDs in the reaction; this reduction has no detrimental effect affording a yield greater than $99 \%$ after $8 \mathrm{~h}$ with a turnover number (TON) of 625 . Reactions involving QDs III and IV (5 wt \%) show a sharp decline in yield and this can be correlated to the low proportion of $\mathrm{Cu}$ doping in these samples. The assumption that the catalysis is taking place on a $\mathrm{Cu}$ center is supported by sample $\mathrm{V}$ whereby no reaction takes place without the presence of $\mathrm{Cu}$ sites. The reaction also proceeds with visible light activation with a yield greater than $99 \%$ after $3 \mathrm{~h}$ using I $(5 \mathrm{~mol} \% \mathrm{Cu})$.

\section{Experimental Section}

Synthesis of [Cu(DEDTC $\left.)_{2}\right]: \mathrm{Cu}\left(\mathrm{S}_{2} \mathrm{CN}\left(\mathrm{CH}_{2} \mathrm{CH}_{3}\right)_{2}\right)_{2}$ was synthesized using a modified procedure outlined by others. ${ }^{[38]}$ 
Synthesis of CdSe QD cores: Luminescent CdSe cores were synthesized following an adapted hot-injection method as described by Roullier et al. with modifications. ${ }^{[20]}$

Shelling of CdSe QDs with ZnS: A shell of $\mathrm{ZnS}$ was synthesized by thermal decomposition of [ $\left.\mathrm{Zn}(\mathrm{DEDTC})_{2}\right]$ according to a procedure outlined by Dethlefsen and Døssing. ${ }^{[23]}$

Synthesis of $\mathrm{CdSe} / \mathrm{ZnS}-\mathrm{CuS}$ core-shell quantum dots: $\mathrm{Cu}$ was doped into the $\mathrm{ZnS}$ shell using a modified procedure outlined by Dethlefsen and Døssing. ${ }^{[23]}$ A mixture of [Zn(DEDTC $\left.)_{2}\right]$ and $[\mathrm{Cu}-$ (DEDTC $)_{2}$ ] composed of different molar ratios was used as the $\mathrm{Zn}$, $\mathrm{Cu}$, and $\mathrm{S}$ precursors, respectively (Table $\mathrm{S} 1$ ).

Received: October 8, 2013

Published online: December 27, 2013

Keywords: click chemistry · copper catalysis · coreshell materials $\cdot$ heterogeneous catalysis $\cdot$ quantum dots

[1] A. Alivisatos, Science 1996, 271, 933-937.

[2] I. L. Medintz, H. T. Uyeda, E. R. Goldman, H. Mattoussi, Nat. Mater. 2005, 4, 435-446.

[3] S. A. Díaz, L. Giordano, T. M. Jovin, E. A. Jares-Erijman, Nano Lett. 2012, 12, 3537-3544.

[4] X. Gao, Y. Gui, R. M. Levenson, L. W. K. Chung, S. Nie, Nat. Biotechnol. 2004, 22, 969-976.

[5] W. Bücking, S. Massadeh, A. Merkulov, S. Xu, T. Nann, Anal. Bioanal. Chem. 2010, 396, 1087-1094.

[6] X. Yang, D. Zhao, K. S. Leck, S. T. Tan, Y. X. Tang, J. Zhao, H. V. Demir, X. W. Sun, Adv. Mater. 2012, 24, 4180-4185.

[7] Z. Han, F. Qiu, R. Eisenberg, P. L. Holland, T. D. Krauss, Science 2012, 338, $1321-1324$.

[8] P. Reiss, M. Protière, L. Li, Small 2009, 5, 154-168.

[9] B. O. Dabbousi, J. Rodriguez-Viejo, F. V. Mikulec, J. R. Heine, H. Mattoussi, R. Ober, K. F. Jensen, M. G. Bawendi, J. Phys. Chem. B 1997, 101, 9463-9475.

[10] A. Pandey, S. Brovelli, R. Viswanatha, L. Li, J. M. Pietryga, V. I. Klimov, S. A. Crooker, Nat. Nanotechnol. 2012, 7, 792-797.

[11] O. Ehlert, A. Osvet, M. Batentschuk, A. Winnacker, T. Nann, J. Phys. Chem. B 2006, 110, 23175-23178.

[12] R. Viswanatha, S. Brovelli, A. Pandey, S. A. Crooker, V. I Klimov, Nano Lett. 2011, 11, 4753-4758.

[13] K. M. Gattás-Asfura, R. M. Leblanc, Chem. Commun. 2003, 2684-2685.

[14] P. Yang, Y. Zhao, Y. Lu, Q.-Z. Xu, X.-W. Xu, L. Dong, S.-H. Yu, ACS Nano 2011, 5, 2147-2154.
[15] H.-Y. Xie, J.-G. Liang, Z.-L. Zhang, Y. Liu, Z.-K. He, D.-W. Pang, Spectrochim. Acta Part A 2004, 60, 2527-2530.

[16] Y.-H. Chan, J. Chen, Q. Liu, S. E. Wark, D. H. Son, J. D. Batteas, Anal. Chem. 2010, 82, 3671-3678.

[17] A. N. Buckley, W. M. Skinner, S. L. Harmer, A. Pring, R. N. Lamb, L.-J. Fan, Y. Yang, Can. J. Chem. 2007, 85, 767-781.

[18] V. V. Rostovtsev, L. G. Green, V. V. Fokin, K. B. Sharpless, Angew. Chem. 2002, 114, 2708-2711; Angew. Chem. Int. Ed. 2002, 41, 2596-2599.

[19] C. W. Tornøe, C. Christensen, M. Meldal, J. Org. Chem. 2002, 67, 3057-3064.

[20] V. Roullier, F. Grasset, F. Boulmedais, F. Artzner, O. Cador, V. Marchi-Artzner, Chem. Mater. 2008, 20, 6657-6665.

[21] R. Beaulac, P. I. Archer, S. T. Ochsenbein, D. R. Gamelin, Adv. Funct. Mater. 2008, 18, 3873-3891.

[22] J. R. Dethlefsen, A. A. Mikhailovsky, P. T. Burks, A. Døssing, P. C. Ford, J. Phys. Chem. C 2012, 116, 23713-23720.

[23] J. R. Dethlefsen, A. Døssing, Nano Lett. 2011, 11, 1964-1969.

[24] G. Hogarth, Prog. Inorg. Chem. 2005, 53, 71-561.

[25] H. Wang, H. Nakamura, M. Uehara, Y. Yamaguchi, M. Miyazaki, H. Maeda, Adv. Funct. Mater. 2005, 15, 603-608.

[26] S. Xu, J. Ziegler, T. Nann, J. Mater. Chem. 2008, 18, 2653-2656.

[27] E. Kuçur, W. Bücking, R. Giernoth, T. Nann, J. Phys. Chem. B 2005, 109, 20355-20360.

[28] W. Q. Peng, G. W. Cong, S. C. Qu, Z. G. Wang, Opt. Mater. 2006, 29, 313-317.

[29] V. Babentsov, J. Riegler, J. Schneider, O. Ehlert, T. Nann, M. Fiederle, J. Cryst. Growth 2005, 280, 502-508.

[30] E. Kucur, J. Riegler, G. A. Urban, T. Nann, J. Chem. Phys. 2003, $119,2333$.

[31] D. H. Son, S. M. Hughes, Y. Yin, A. P. Alivisatos, Science 2004, 306, 1009-1012.

[32] M. H. B. Stowell, T. M. McPhillips, D. C. Rees, S. M. Soltis, E. Abresch, G. Feher, Science 1997, 276, 812-816.

[33] R. H. Nagaraj, D. R. Sell, M. Prabhakaram, B. J. Ortwerth, V. M. Monnier, Proc. Natl. Acad. Sci. USA 1991, 88, 10257-10261.

[34] P.-Y. Liu, N. Jiang, J. Zhang, X. Wei, H.-H. Lin, X.-Q. Yu, Chem Biodiversity 2006, 3, 958-966.

[35] M. A. Tasdelen, Y. Yagci, Tetrahedron Lett. 2010, 51, 6945-6947.

[36] M. A. Tasdelen, G. Yilmaz, B. Iskin, Y. Yagci, Macromolecules 2012, 45, 56-61.

[37] B. J. Adzima, Y. Tao, C. J. Kloxin, C. A. Deforest, K. S. Anseth, C. N. Bowman, Nat. Chem. 2011, 3, 256-259.

[38] R. Golding, C. Harris, K. Jessop, W. Tennant, Aust. J. Chem. 1972, 25, 2567. 